\title{
How university and industry knowledge interact to determine local entrepreneurship
}

\author{
Massimiliano Guerini ${ }^{\mathrm{a}}$ and Cristina Rossi-Lamastra ${ }^{\mathrm{b}, *}{ }^{\mathrm{a}}$ Università di Pisa, DESTEC, Pisa, Italy \\ ${ }^{\mathrm{b}}$ Department of Management, Economics and Industrial Engineering, Politecnico di Milano, via Lambruschini \\ 4/c, Milano 20125, Italy
}

This article discusses and empirically investigates whether and how university knowledge and industry knowledge interact to determine the creation of knowledge-intensive firms (KIFs) in a geographic area. In line with the knowledge spillover theory of entrepreneurship (KSTE), we find that both knowledge types matter for stimulating local entrepreneurship. However, our findings document that university knowledge exerts an effect just in areas where industry knowledge is low. In other words, the two types of knowledge do not generate synergetic gains, but are substitutes.

Keywords: new firm creation; industry knowledge; university knowledge; knowledge spillover theory of entrepreneurship

JEL Classification: L29; O33

\section{Introduction and Theoretical Background}

Knowledge-intensive firms (KIFs) have positive effects on regional growth and thus contribute to economic devel-opment (Audretsch, 1995). Scholars championing the knowledge spillover theory of entrepreneurship (hereafter: KSTE, Acs et al., 2009) agree that the knowledge that spills over territories from local universities and incumbent firms positively affects new KIFs creation in a geographic area (Audretsch and Lehmann, 2005). First, knowledge generated by universities (hereafter: university knowledge) and incumbent firms (hereafter: industry knowledge) provides opportunities that prospective entrepreneurs can commercially exploit through the creation of new KIFs (Acs and Plummer, 2005). Moreover, this knowledge can be leveraged by prospective entrepreneurs for solving complex technological problems and it is thus valuable for new KIFs creation (Cohen et al., 2002).
Since the seminal work of Marshall (1920), it is common wisdom that incumbent firms generate knowledge that spills over in their territories to stimulate local entrepreneurship. More recently, several studies have empirically detected the positive influence of university knowledge on new KIFs creation at the local level (Acosta et al., 2011; Bonaccorsi et al., 2013). This article adds to the literature by offering rigorous empirical evidence on how university and industry knowledge interact to affect knowledge-intensive entrepreneurship at the local level. We begin with the premise that industry and university knowledge have different characteristics. While the former has an applied nature, the latter is only partially formed and rarely has an immediate commercial application (e.g. Stephan, 2012). Accordingly, we put forth the following research question: does the simultaneous availability of university and industry knowledge in a geographic area engenders synergistic gains, or in contrast, are the two knowledge types substitutable?

\footnotetext{
*Corresponding author. E-mail: cristina1.rossi@polimi.it
} 
Answering this research question is undoubtedly relevant for policymakers who design policies to support knowledge-intensive entrepreneurship. Indeed, finding that university knowledge magnifies the effects of local availability of industry knowledge would offer further support for the implementation of technology transfer policies in well-developed areas. Likewise, a substitution effect would lend support for policies that establish a university presence in areas where the productive system is lagging behind. The article is organized as follows: in Section II, we describe our data and methods; Section III illustrates results; and Section IV concludes.

\section{Data and Methodology}

The dependent variable is the number of new KIFs established during 2010 in the Italian province $i$ $\left(N e w K I F_{i}\right)$. As NewKIF is a count variable and is characterized by over-dispersion, we estimate a negative binomial regression model (Audretsch and Lehmann, 2005) ${ }^{1}$ having the following specification:

$$
\begin{aligned}
\text {NewKIF}_{i}= & \exp \left(\alpha+\beta_{1} U N I_{i}+\beta_{2} K I F_{i}\right. \\
& \left.+\beta_{3} U N I_{i} \times K I F_{i}+\gamma Z_{i}+\varepsilon_{i}\right)
\end{aligned}
$$

with $i$ denoting the Italian province. The variable $U N I_{i}$ accounts for the availability of university knowledge in province $i$. It is expressed as the ratio between the number of scientific publications and the number of researchers (full professors, associate professors and assistant professors) at universities located in province $i . K I F_{i}$ refers to the local availability of industry knowledge. It is expressed as the number of incumbent KIFs per thousand inhabitants in province $i . U N I_{i} \times K I F i$ is the interaction between the two variables. $Z_{i}$ is a set of control variables accounting for other factors, which, according to the literature (Kerr and Glaeser, 2009), are likely to affect new KIF creation at the local level. These factors include the size of province $i$ measured in $1000 \mathrm{~km}^{2}\left(S I Z E_{i}\right)$, population density $\left(\right.$ Density $\left._{i}\right)$, the logarithmic distance $(\mathrm{km})$ of the province $i$ from the administrative capital of the NUTS2 region in which the province is located (Dist_Capital ${ }_{i}$ ), the percentage of the population that is $20-39$ years old out of the total population in province $i$ (Pop_20_39 $)$, the percentage of the population living in mountainous areas out of the total population in the province $i\left(\right.$ Pop_Moun $\left._{i}\right)$ and a dummy variable indicating whether there is at least one business incubator $\left(B I_{i}\right)$ in the province. Finally, dummy variables at the NUTS1 level (i.e. Italian macro-areas) are added to take into account macro-regional characteristics that may affect new KIF creation. Table 1 reports the summary statistics and the correlation matrix. ${ }^{2}$

Data used to test Equation 1 come from several information sources. Data on new KIFs in 2010 and on incumbent KIFs in each Italian province in 2009 are extracted from the MOVIMPRESE database, maintained by the Union of the Italian Chambers of Commerce (see http:// www.infocamere.it/movimprese). Data on Italian universities are extracted from the EUMIDA database, which has been developed under a European Commission tender (see EUMIDA (2010) for details). Both university and industry data are classified into geographical units (Italian pro-vinces) according to the location of new KIFs and uni-versities. We used the Italian National Institute of Statistics (ISTAT) and the Istituto Tagliacarne databases to collect territorial data and information on firms' demographics for 2009 (see http://www.tagliacarne.it). Finally, we down-loaded the list of Italian science parks and business incu-bators in 2009 from the website of the Association of Italian Science and Technology Parks (APSTI).

\begin{tabular}{|c|c|c|c|c|c|c|c|c|c|c|c|c|c|c|c|}
\hline Variable & $\mathrm{N}$ & Mean & SD & Min & Max & (1) & (2) & (3) & (4) & (5) & (6) & (7) & $(8)$ & (9) & (10) \\
\hline$N e w K I F_{i}$ & 103 & 46.22 & 105.86 & 1.00 & 1008.00 & 1.00 & & & & & & & & & \\
\hline Density $_{i}$ & 103 & 0.25 & 0.34 & 0.38 & 2.63 & 0.60 & 1.00 & & & & & & & & \\
\hline Dist_Capital $_{i}$ & 103 & 3.46 & 1.75 & 0.00 & 5.17 & -0.34 & -0.36 & 1.00 & & & & & & & \\
\hline Pop_20_39 $i$ & 103 & 25.53 & 1.72 & 19.97 & 28.87 & -0.02 & 0.04 & 0.07 & 1.00 & & & & & & \\
\hline Pop_Moun $_{i}$ & 103 & 18.36 & 28.45 & 0.00 & 100.00 & -0.13 & -0.20 & -0.15 & -0.14 & 1.00 & & & & & \\
\hline$B I_{i}$ & 103 & 0.39 & 0.49 & 0.00 & 1.00 & 0.23 & 0.24 & -0.28 & -0.06 & -0.08 & 1.00 & & & & \\
\hline Size $_{i}$ & 103 & 2.93 & 1.75 & 0.21 & 7.68 & 0.04 & -0.27 & -0.24 & 0.26 & 0.20 & 0.08 & 1.00 & & & \\
\hline$K I F_{i}$ & 103 & 2.15 & 0.87 & 0.71 & 4.43 & 0.53 & 0.36 & -0.33 & -0.34 & -0.08 & 0.26 & -0.08 & 1.00 & & \\
\hline (9) $U N I_{i}$ & 103 & 0.69 & 1.24 & 0.00 & 5.26 & 0.43 & 0.24 & -0.30 & 0.02 & -0.17 & 0.35 & 0.18 & 0.30 & 1.00 & \\
\hline (10) $K I F_{i} \times U N I_{i}$ & 103 & 1.81 & 3.75 & 0.00 & 20.90 & 0.64 & 0.37 & -0.42 & -0.06 & -0.16 & 0.34 & 0.15 & 0.52 & 0.89 & 1.00 \\
\hline
\end{tabular}

Table 1. Summary statistics and correlation matrix

\footnotetext{
${ }^{1}$ The presence of over-dispersion is confirmed by the likelihood-ratio test under the null hypothesis that the over-dispersion coefficient is zero. The null hypothesis is rejected at $1 \%$ significance level.

${ }^{2}$ In the estimation of Equation 1, we standardize all the variables with the exception of dummy variables to ease the interpretation of the results. However, Table 1 reports unstandardized values.
} 


\section{Results and Discussion}

Table 2 reports the results of the econometric estimates. Column I contains econometric estimates of Equation 1 without the interaction term $\left(\beta_{3}\right)$, which is instead included in estimates in column II. To ease the interpretation of estimated coefficients, we report in Table 2 the incidence rate ratios (IRRs), i.e. $\exp (\beta) .^{3}$

Results for control variables are in line with the literature. Population density $\left(\right.$ Density $\left._{i}\right)$, the share of the population between 20 and 39 years of age (Pop_32_29i $)$, the presence of business incubators $\left(B I_{i}\right)$ and the size of the province $\left(\right.$ Size $\left._{i}\right)$ are associated with an increase (significant at $1 \%$ with the exception $B I_{i}$ ) in the number of new KIFs (i.e. IRR > 1). The coefficient of Pop_Moun $i$ is negative (i.e. IRR $<1$ ) and is significant at $1 \%$, while Dist Capital $_{i}$ is not significant.

Let us now turn our attention to the variables of interest. Looking at column I of Table 2, we find evidence of positive knowledge spillovers coming from both local incumbent KIFs and universities. Both the coefficients of $K I F_{i}$ and $U N I_{i}$ are indeed positive (i.e. IRR $>1$ ) and significant at $1 \%$. Specifically, a one SD increase in $K I F_{i}$ and $U N I_{i}$ leads to a $72 \%$ and $13 \%$ increase in the number of new KIFs in province $i$, respectively. Column II confirms these results. Moreover, the coefficient of the interaction term $U N I_{i} \times K I F_{i}$ is not significant. However, given the nonlinear specification of the negative binomial regression model, looking at the significance and the magnitude of the interaction term's coefficient (i.e. $\beta_{3}$ ) is

Table 2. Impact of university and industry knowledge on new KIFs creation

\begin{tabular}{lll}
\hline & Model I & Model II \\
\hline Density $_{i}$ & $1.247(0.070)^{* * *}$ & $1.267(0.081)^{* * *}$ \\
Dist_Capital $_{i}$ & $0.939(0.050)$ & $0.931(0.030)$ \\
Pop_20_39 $_{i}$ & $1.316(0.112)^{* * *}$ & $1.316(0.114)^{* * *}$ \\
Pop_Moun $_{i}$ & $0.847(0.041)^{* * *}$ & $0.846(0.041)^{* * *}$ \\
BI $_{i}$ & $1.296(0.151)^{* *}$ & $1.280(0.147)^{* *}$ \\
Size $_{i}$ & $1.229(0.078)^{* * *}$ & $1.237(0.081)^{* * *}$ \\
KIF $_{i}$ & $1.725(0.145)^{* * *}$ & $1.757(0.160)^{* * *}$ \\
$U_{N} I_{i}$ & $1.128(0.053)^{* * *}$ & $1.143(0.047)^{* * *}$ \\
KIF $_{i} \times U N I_{i}$ & & $0.961(0.035)$ \\
Observations $_{\text {Log-likelihood }}$ & 103 & 103 \\
\hline
\end{tabular}

Notes: Negative binomial regression estimates. The dependent variable is the number of new KIFs in the province. IRRs are reported. SEs are in brackets. Constant and NUTS1 dummies are omitted.

$* *$ and $* * *$ indicate significance at the $5 \%$ and $1 \%$ levels, respectively. not sufficient to assess the existence of an interaction effect between university and industry knowledge. Accordingly, we employ King et al.'s (2000) simulationbased methodology to interpret the interaction effect and present the results graphically. Figure 1 illustrates the difference in the expected value of the number of new KIFs between a province $i$ in which the value of university knowledge is high (i.e. $U N I_{i}$ is set to the mean value plus $1 \mathrm{SD}$ ) and a province $j$ in which the value of university knowledge is low (i.e. a province without universities), depending on the availability of industry knowledge in the province (in the horizontal axis, we report the standar-dized value of the variable $K I F_{i}$ ). Finally, the dotted line means that the difference is significant at the $5 \%$ level. The significance level has been estimated by Zelner's (2009) method.

Figure 1 highlights that for low values of $K I F_{i}$, the expected number of new KIFs in the province is significantly higher if university knowledge is high. However, for high values of $K I F_{i}$, this difference is not significant. In other words, the results suggest that if industry knowledge is low, provinces with higher availability of university knowledge experience an increase in the number of new KIFs. However, when the local availability of industry knowledge is high, the effect of university knowledge on knowledge-intensive entrepreneurship at the local level is negligible.

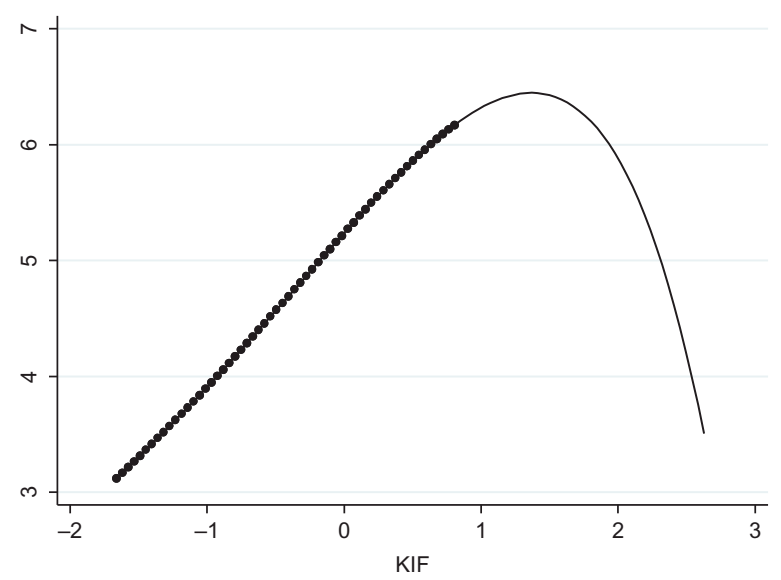

Fig. 1. Difference in the expected value of new KIFs between provinces with high and low university knowledge depending on industry knowledge

Notes: Difference in the expected value of New $K I F_{i}$ between provinces with high (one SD above the mean) and low (zero) values of university knowledge $\left(U N I_{i}\right)$. In the horizontal axis, we report the standardized value of industry knowledge $\left(K I F_{i}\right)$. The dotted line shows that the difference is significant at the $5 \%$ level (Zelner, 2009).

\footnotetext{
${ }^{3}$ The IRR is the ratio at which the dependent variable increases (or decreases) for a one unit increase in the explanatory variable while holding all other variables in the model constant. Since all continuous variables in the model are standardized, a one-unit increase corresponds to a one SD increase.
} 


\section{Conclusion}

The results reported in this article are in line with prior works documenting that the local availability of university and industry knowledge has a positive impact on new KIF creation in a geographic area (Acosta et al., 2011; Bonaccorsi et al., 2013). More importantly, our study adds to the KSTE (Acs et al., 2009) by showing that no synergistic gains emerge from the simultaneous presence of university and industry knowledge in a given area. Conversely, university knowledge favours the creation of new KIFs only in areas where the availability of knowledge generated by incumbent KIFs is limited. In other words, the two types of knowledge are substitutable in stimulating knowledge-intensive entrepreneurship at the local level.

Our work has interesting policy implications. It suggests that public support for the creation and transfer of university knowledge may be an effective mechanism to support the creation of new KIFs in geographic areas where knowl-edge-intensive entrepreneurship is lagging.

\section{References}

Acosta, M., Coronado, D. and Flores, E. (2011) University spill-

overs and new business location in high-technology sectors: Spanish evidence, Small Business Economics, 36, 365-76. Acs, Z., Audretsch, D. B., Braunerjhelm, P. et al. (2009) The

knowledge spillover theory of entrepreneurship, Small Business Economics, 32, 15-30.
Acs, Z. and Plummer, L. A. (2005) Penetrating the 'knowledge filter' in regional economies, Annals of Regional Science, 39, 439-56.

Audretsch, D. B. (1995) Innovation and Industry Evolution, MIT Press, Cambridge.

Audretsch, D. B. and Lehmann, E. E. (2005) Does the knowledge spillover theory of entrepreneurship hold for regions?, Research Policy, 34, 1191-202.

Bonaccorsi, A., Colombo, M. G., Guerini, M. et al. (2013) The impact of local and external university knowledge on the creation of knowledge intensive firms: evidence from the Italian case, Small Business Economics, doi: 10.1007/ s11187-013-9536-2.

Cohen, W. M., Nelson, R. R. and Walsh, J. P. (2002) Links and impacts: the influence of public research on industrial R\&D, Management Science, 48, 1-23.

EUMIDA (2010) Feasibility study for creating a European University Data Collection [Contract No. RTD/C/C4/2009/ 0233402], European Communities, Brussels. Available at http://ec.europa.eu/research/era/docs/en/eumida-finalreport. pdf (accessed 23 November 2013).

Kerr, W. R. and Glaeser, E. L. (2009) Local industrial conditions and entrepreneurship: how much of the spatial distribution can we explain?, Journal of Economics and Management Strategy, 18, 623-63.

King, G., Tomz, M. and Wittenberg, J. (2000) Making the most of statistical analyses: improving interpretation and presentation, American Journal of Political Science, 44, 347-61.

Marshall, A. (1920) Industry and Trade, Macmillan and Co., London.

Stephan, P. (2012) How Economics Shapes Science, Harvard University Press, Cambridge.

Zelner, B. A. (2009) Using simulation to interpret results from logit, probit, and other nonlinear models, Strategic Management Journal, 30, 1335-48. 